\title{
Composição físico-química, microbiológica e rendimento do filé de tilápia tailandesa (Oreochromis niloticus)
}

Physicochemical and microbiological composition and yield of thai-style tilapia fillets (Oreochromis niloticus)

\author{
Marcia Regina SIMÕES ${ }^{1,2 *}$, Carmelita de Fátima Amaral RIBEIRO ${ }^{3}$, Suezilde da Conceição Amaral RIBEIRO ${ }^{4}$, \\ Kil Jin PARK ${ }^{3}$, Fernanda Elizabeth Xidieh MURR ${ }^{1}$
}

\begin{abstract}
Resumo
Foram determinados o rendimento do filé e a composição físico-química da tilápia quanto ao teor de umidade, proteína, cinza, lipídeos e atividade de água. Para as análises, foram utilizados 19 exemplares de tilápia com peso médio e comprimento de $989,6 \mathrm{~g}$ e $38,9 \mathrm{~cm}$, respectivamente. Os peixes foram pesados, medidos (comprimento, largura e espessura) e após a filetagem calculou-se o rendimento. Foi realizada a determinação da composição físico-química, que apresentou teores de: 77,13\% de umidade; 2,60\% lipídios; 19,30\% proteína; 1,09\% cinza; e atividade de água de 0,983. As relações de peso filé/peixe e peixe/resíduo apresentaram boas correlações lineares. Foi realizada também a análise microbiológica do peixe in natura; a matéria-prima estava dentro dos limites exigidos pela legislação brasileira, portanto apta para o processamento e/ou consumo.

Palavras-chave: composição centesimal; filetagem; subprodutos da filetagem; pescado.
\end{abstract}

\begin{abstract}
The fillet yield of Thai-style tilapia and its physicochemical composition, including moisture content, protein, ash lipids and water activity, were determined. The analysis involved 19 specimens of tilapia with average weight and length of $989.6 \mathrm{~g}$ and $38.9 \mathrm{~cm}$, respectively. The fish were weighed, measured (length, width and thickness), filleted, and the yield was calculated. The chemical composition presented the following contents: $77.13 \%$ moisture, $2.60 \%$ lipids, $19.30 \%$ protein, $1.09 \%$ ash, and 0.983 water activity. The fillet/fish to fish/residue weight ratios presented good linear correlations. The raw fish was also subjected to a microbiological analysis, which indicated that it met the safety limits established by Brazilian legislation and was therefore safe for processing and consumption.

Keywords: approximate composition; filleting; filleting by-products; fish.
\end{abstract}

\section{Introdução}

A tilápia apresenta requisitos típicos dos peixes preferidos do consumidor, tais como carne branca de textura firme, sabor delicado e fácil filetagem, não tendo espinha em "Y" e nem odor desagradável ${ }^{22}$. Possui também características que a colocam no pódio das principais espécies cultiva das comercialmente, como: facilidade de reprodução e obtenção de alevinos, a possibilidade de manipulação hormonal do sexo para produção de machos, aceitação de diversos alimentos, excelente crescimento em cultivo intensivo e resistência às doenças.

O estoque inicial de tilápia do Nilo, introduzida no Brasil foi formado por 60 indivíduos provenientes da Estação de Piscicultura de Bouaké, Costa do Marfim, África, NUGENT ${ }^{15}$, em 1971 por meio do DNOCS, em Pentecostes, Estado do Ceará4.

A tilápia do Nilo da linhagem Chitralada teve sua introdução oficial no Brasil no ano de 1996, com 20800 exemplares

Recebido para publicação em 27/9/2006

Aceito para publicação em 18/7/2007 (001869)

Departamento de Engenharia de Alimentos - DEA,

Faculdade de Engenharia de Alimentos - FEA,

Universidade Estadual de Campinas - UNICAMP,

CP 6121, CEP 13083-970, Campinas - SP, Brasil,

E-mail:marciarsimoes@yahoo.com.br

2 Universidade Estadual do Oeste do Paraná - UNIOESTE, Toledo - PR, Brasil

Faculdade de Engenharia Agrícola - FEAGRI

Universidade Estadual de Campinas - UNICAMP, Campinas - SP, Brasil,

E-mail:kil@agr.unicamp.br

4 Departamento de Agroindústria

Escola Agrotécnica Federal de Castanhal - EAFC, Castanhal - PA, Brasil

*A quem a correspondência deve ser enviada importados do Agricultural and Aquatic Systems, do Asian Institute of Tecnology (AIT), com sede na Tailândiai ${ }^{31}$. No entanto, a sua importação foi realizada pela Alevinopar (Associação de Produtores de Alevinos do Estado do Paraná) e SEAB (Secretaria da Agricultura e Abastecimento do Paraná).

Assim, as linhagens de tilápia do Nilo, existentes no Brasil, possuem duas origens, a tilápia de Bouaké, originária da Costa do Marfim, região oeste da África e a tilápia tailandesa ou chitralada, originária da Tailândia, que, por sua vez, tinha importado do Japão, e cujo estoque teve origem no Egito, região leste da África ${ }^{14}$.

No Brasil, a expansão da tilápia tem sido impulsionada pela demanda de mercado por sua boa aceitação pela população, quanto ao sabor, valor nutritivo e preços baixos. O grande interesse pela tilápia também está nos piscicultores que a estão produzindo em todo o País, principalmente pela facilidade de cultivo, o que desperta o interesse das indústrias em processar este peixe.

O valor nutritivo e os preços dos peixes dependem da textura da carne, da composição química, do rendimento e de fatores relacionados aos métodos de captura e beneficiamento. O conhecimento da composição química dos pescados é de fundamental importância para a padronização dos produtos alimentares na base de critérios nutricionais, pois fornece subsídios para decisões de caráter dietário, acompanhamento de processos industriais e seleção de equipamentos para otimização econômico-tecnológica ${ }^{6}$. 
SOUZA $^{22}$ determinou o rendimento do filé de tilápia (Oreochromis niloticus), em torno de 34,6 a 36,6\%, porém, encontrou diferenças significativas quanto aos métodos de filetagem usados. No processamento da tilápia, é importante destacar que o peixe gera grande quantidade de resíduos que podem ser aproveitados na fabricação de outros produtos alimentícios.

Segundo BRUSHI ${ }^{3}$, muitas tecnologias têm surgido com possíveis utilizações dos resíduos como fontes alimentares, transformando-os em produtos nutritivos e com boa aceitação no mercado, como o caso do surimi, que pode ser obtido através da carne que fica aderida à espinha dorsal do pescado no processo de filetagem e outros produtos como patês, bolinhos e fishburguers. Considerando a importância de se conhecer o valor nutritivo e potencial de carne e resíduos da tilápia, o principal objetivo deste trabalho foi obter a caracterização física, a composição química e a análise microbiológica e determinar o rendimento do filé e resíduos gerados no processamento da tilápia.

\section{Material e métodos}

\subsection{Material}

A matéria-prima constou de um lote de $30 \mathrm{~kg}$ de tilápia Tailandesa coletado de um pesqueiro comercial de Cosmópolis (SP). Os peixes foram coletados através de uma rede de pesca, eviscerados no local e lavados em água corrente. Após serem retirados do pesqueiro foram armazenados em gelo até serem levados ao Laboratório de Medidas Físicas da UNICAMP. Os peixes foram lavados em água corrente e em água clorada para retirada do muco superficial e outras impurezas. Cinco peixes inteiros foram congelados a $-18{ }^{\circ} \mathrm{C}$ até serem submetidos à análise microbiológica. Para as análises físicoquímicas, utilizou-se o filé sem pele que foi homogeneizado em um liquidificador.

\subsection{Avaliação microbiológica}

Foram realizadas as análises microbiológicas de Salmonella sp. e Estaphylococcus coagulase positiva para o pescado. As análises foram realizadas em 5 amostras de tilápia levadas inteiras até a análise. Para as análises, foram retirados $25 \mathrm{~g}$ do filé sem pele para análise de Salmonella sp. e 25 g para a análise de Estaphylococcus coagulase positiva. As amostras foram homogeneizadas em Stomacher (homogeneizador de pistão). As análises foram realizadas de acordo com a Resolução-RDC n ${ }^{\circ} 12$, de 2 de janeiro de 2001 da Agência Nacional de Saúde (ANVISA) ${ }^{1}$, no laboratório de Higiene do Departamento de Tecnologia de Alimentos da Faculdade de Engenharia de Alimentos da UNICAMP.

\subsection{Avaliação físico-química da matéria-prima}

\section{Caracterização física}

Foi realizada com um lote de 19 peixes eviscerados de pesqueiro comercial em Cosmópolis - SP. Foram verificados o comprimento, a largura e a espessura com o auxílio de trena e paquímetro, e o peso das amostras em balança analítica. Foram calculados os rendimentos dos filés e resíduos, definidos neste trabalho como cabeça e coluna vertebral.

\section{Análise físico-química}

As análises descritas a seguir foram feitas em triplicata.

- Umidade: este método baseia-se na evaporação da água presente no alimento em estufa a vácuo a $70{ }^{\circ} \mathrm{C}$ e $660 \mathrm{mmHg}$, até peso constante ${ }^{2}$;

- Cinza: determinada por incineração da matéria orgânica, em forno mufla a $550{ }^{\circ} \mathrm{C}$, até peso constante ${ }^{2}$;

- Proteína: foi utilizado o método de Kjeldahl para determinar o nitrogênio total. Este método baseia-se no conteúdo de nitrogênio da matéria orgânica, incluindo o nitrogênio protéico propriamente dito e outros compostos nitrogenados não protéicos, tais como aminas, aminoácidos, entre outros. Neste caso, o resultado foi expresso em proteínas bruta ou total, utilizando-se para o cálculo o fator $6,25^{2}$;

- Lipídeos: os lipídeos foram determinados pelo método de BLIGH e DYER (1959), utilizando-se clorofórmio e metanol como solvente ${ }^{2}$;

- Atividade de água: baseia-se na medida direta a $25^{\circ} \mathrm{C}$ da amostra acondicionada em cápsula plástica, em equilíbrio com a atmosfera interna do equipamento, através do instrumento Aqualab, modelo CX-2T-Decagon. O valor da atividade de água é registrado quando há a formação da primeira gota de orvalho em função do equilíbrio alcançado entre a fase líquida presente na amostra, e a fase gasosa.

\section{Resultados e discussão}

\subsection{Avaliação microbiológica}

Os resultados das análises microbiológicas efetuadas conforme a resolução - RDC n ${ }^{\circ} 12$, de 02 de janeiro de 2001, da Agência de Vigilância Sanitária - ANVISA estão apresentados na Tabela 1.

Tabela 1. Análise microbiológica da Tilápia in natura.

\begin{tabular}{lcc}
\hline \multicolumn{1}{c}{ Análises } & Tilápia in natura & Legislação \\
\hline $\begin{array}{l}\text { Salmonella } \\
\text { Staphylococcus }\end{array}$ & Ausência em $25 \mathrm{~g}$ & Ausência em $25 \mathrm{~g}$ \\
coagulase positiva & $<10^{2} \mathrm{UFC}^{*} \cdot \mathrm{g}^{-1}$ & Max. $10^{3} \cdot \mathrm{g}^{-1}$ \\
*UFC: Unidades formadoras de colônia.
\end{tabular}

A Tabela 1 indica que a matéria-prima estava dentro dos limites exigidos pela legislação brasileira, portanto apta para o processamento e/ou consumo.

As ausências de Staphylococcus coagulase positiva e Salmonella confirmam que os procedimentos sanitários e higiênicos foram corretamente seguidos desde a captura até a preparação da matéria-prima. Se fosse confirmada a presença 
destas bactérias, a matéria-prima deveria ser descartada para impedir qualquer tipo de toxinfecções alimentares. No Brasil, pesquisas realizadas em diferentes regiões do País, mostraram a ocorrência de $S$. aureus em pescado ${ }^{8,11}$.

O gênero Staphyloccocus é o agente responsável por aproximadamente $45 \%$ das toxinfecções do mundo. O Staphyloccocus aureus é um dos agentes patogênicos mais comuns, responsável por surtos de origem alimentar, sendo normalmente transmitido aos alimentos por manipuladores ${ }^{7}$.

Tilápias (Oreochromis niloticus) recém-capturadas foram analisadas quanto à presença de $S$. aureus segundo VIEIRA et al. ${ }^{29}$. Todas as amostras apresentaram valores que variaram de $<10$ a $1,06.10^{3}$ UFC.g ${ }^{-1}$.

O habitat da Salmonella é o trato intestinal e sua presença indica provável contaminação fecal de fontes humanas ou animais. Peixes capturados em águas não poluídas estão isentas de Salmonella pelo fato desta não fazer parte da microbiota natural do pescado. Sua presença neste alimento é oriunda normalmente do manuseio ou contato com superfícies higienizadas inadequadamente. A presença de Salmonella é razão suficiente para que a amostra seja condenada ${ }^{12}$.

\subsection{Caracterização física da matéria-prima}

Um lote de, aproximadamente $30 \mathrm{~kg}$ de tilápia eviscerada, obtido no pesqueiro BT (Cosmópolis - SP), apresentou as seguintes características físicas, como mostra a Tabela 2 .

Tabela 2. Caracterização física de Tilápia in natura.

\begin{tabular}{lrrrr}
\hline $\begin{array}{c}\text { Características } \\
\text { físicas }\end{array}$ & Mínimo & Máximo & Média ${ }^{*}$ ) & $\begin{array}{r}\text { Desvio } \\
\text { padrão }\end{array}$ \\
\hline Peso total (g) & 447,9 & 1369,6 & 989,6 & 326,0 \\
Comprimento (cm) & 28,0 & 43,0 & 38,9 & 9,4 \\
Largura (cm) & 12,0 & 18,0 & 16,2 & 4,0 \\
Espessura (cm) & 3,0 & 4,9 & 3,8 & 1,0 \\
Filé com pele (g) & 91,0 & 306,5 & 214,1 & 73,9 \\
Filé sem pele(g) & 64,5 & 261,6 & 172,0 & 63,8 \\
Pele (g) & 17,8 & 56,2 & 36,4 & 11,9 \\
Cabeça (g) & 159,4 & 287,0 & 288,4 & 92,0 \\
Espinhas (g) & 99,7 & 459,6 & 264,4 & 96,7 \\
\hline *médias relativas a 19 exemplares de Tilápia. & & &
\end{tabular}

Em média os peixes apresentaram 989,6 \pm 326,0 g, $38,9 \pm 9,4 \mathrm{~cm}, 16,2 \pm 4,0 \mathrm{~cm}$ e $3,8 \pm 1,0 \mathrm{~cm}$ que corresponderam ao peso total, comprimento, largura e espessura, respectivamente. A relação entre a largura e o peso total da tilápia está representada na Figura 1.

A largura variou desde 12,0 até $18,0 \mathrm{~cm}$, com uma média de 16,2 $\pm 4,0 \mathrm{~cm}$, e o peso da tilápia desde 447,9 até 1369,6 g, com a média de $989,6 \pm 326,0$ g. A relação entre o peso total e o peso do filé da tilápia está apresentada na Figura 2.

O peso do filé com pele variou de 91,0 até $306,5 \mathrm{~g}$, com média de $214,1 \pm 73,9$ g e o filé sem pele variou de 64,5 até $261,6 \mathrm{~g}$, com média de $172,0 \pm 63,8 \mathrm{~g}$.

Os resíduos foram definidos como a somatória da cabeça e coluna vertebral gerada no processamento da tilápia, e sua relação com o peso total está apresentada na Figura 3.

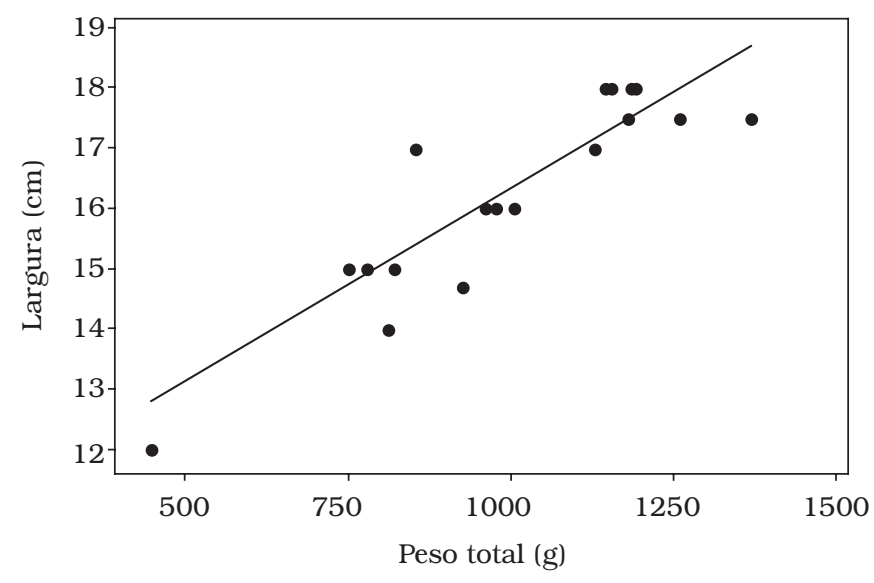

Figura 1. Relação entre a largura e o peso total da tilápia.
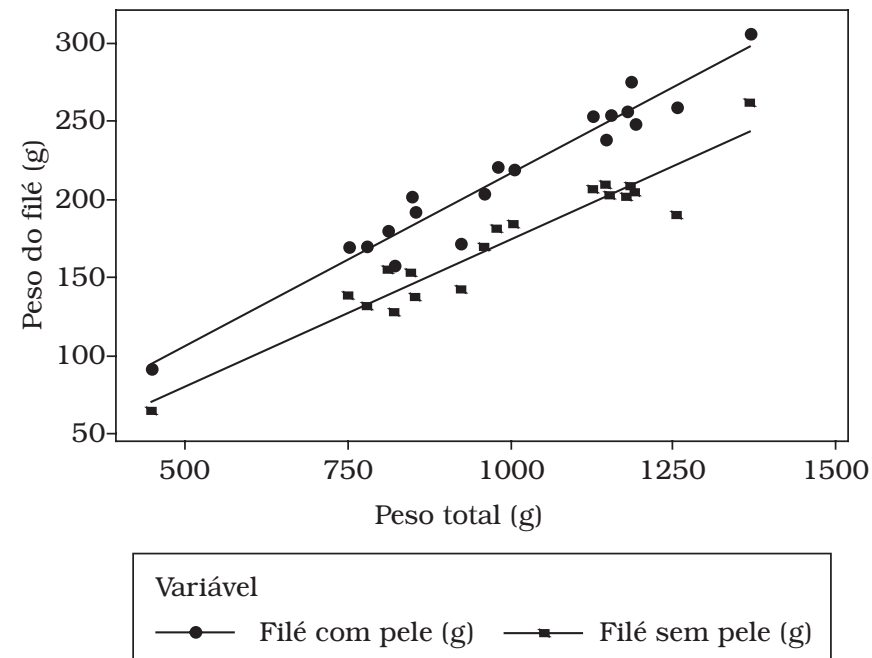

Figura 2. Relação entre o peso total e o peso do filé de tilápia com pele e sem pele.

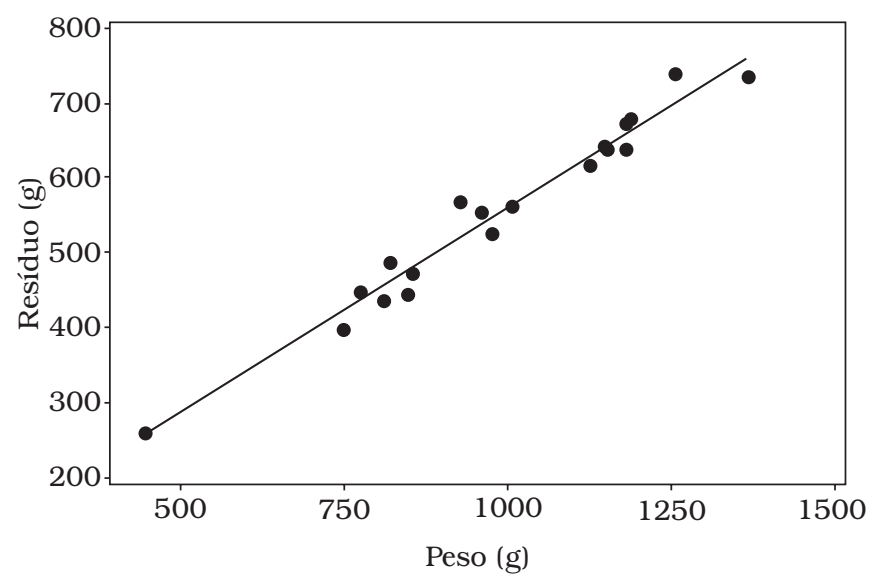

Figura 3. Relação entre o peso total e os resíduos de tilápia.

O valor dos resíduos variou de 259,1 até 738,4 g com média de 552,5 $\pm 125,6 \mathrm{~g}$.

A Tabela 3 mostra os modelos de regressão linear obtidos para as Figuras de 1 a 3 e seus respectivos coeficientes de 
determinação $\left(\mathrm{R}^{2}\right)$. A regressão foi significativa ao nível de $5 \%$ para todos os modelos propostos. A relação entre largura e peso apresentou o menor coeficiente de determinação, 75,7\%.

Tabela 3. Modelos de regressão e coeficiente de determinação $\left(R^{2}\right)$.

\begin{tabular}{lc}
\hline Equações de regressão & $\mathrm{R}^{2}(\%)$ \\
\hline Largura $=9,92+0,00642$ peso $(\mathrm{g})$ & 75,7 \\
Filé com pele $=-4,4+0,221$ peso $(\mathrm{g})$ & 94,1 \\
Filé sem pele $=-12,8+0,187$ peso $(\mathrm{g})$ & 91,6 \\
Resíduo $=6+0,552$ peso $(\mathrm{g})$ & 98,0 \\
\hline
\end{tabular}

SANTOS ${ }^{21}$, trabalhando com duas espécies de tilápia, a Tailandesa e a Suprema, utilizou uma equação logística para descrever a idade da tilápia em função do peso. Utilizando esta equação para os pesos obtidos neste trabalho, a idade da tilápia Tailandesa encontra-se entre 281 e 407 dias, sendo, portanto, tilápias adultas.

A Tabela 4 mostra os valores médios da filetagem de carcaça, filés e subprodutos da filetagem.

Tabela 4. Valores médios de rendimento de carcaça, filé e subprodutos da filetagem da tilápia.

\begin{tabular}{|c|c|c|c|c|c|}
\hline \multicolumn{3}{|c|}{ Rendimento (\%) } & \multicolumn{3}{|c|}{ Subproduto da filetagem (\%) } \\
\hline \multirow{2}{*}{$\begin{array}{c}\text { Carcaça sem } \\
\text { cabeça }\end{array}$} & \multirow[t]{2}{*}{ Filé } & \multirow{2}{*}{$\begin{array}{l}\text { Filé com } \\
\text { pele }\end{array}$} & \multirow{2}{*}{$\begin{array}{c}\text { Pele } \\
\text { bruta }\end{array}$} & \multicolumn{2}{|c|}{ Resíduos } \\
\hline & & & & Cabeça & Espinha \\
\hline 70,85 & 17,38 & 21,63 & 3,68 & 29,14 & 26,71 \\
\hline
\end{tabular}

Considerando o rendimento da carcaça sem cabeça, SOUZA e MARANHÃO ${ }^{27}$ obtiveram um rendimento de 75,61 e 78,18\% para pesos de tilápia do Nilo variando de 300-400 g e 401-500 g, estes valores foram levemente superiores ao encontrado neste experimento que foi de $70,85 \%$. SOUZA et al. ${ }^{24}$ relata rendimentos inferiores, de 57,13 a $61,91 \%$ em função da categoria de peso de 250-400 g e 401-550 g, respectivamente.

Os valores obtidos de rendimento do filé, 17,38\% (filé sem pele) e $21,63 \%$ (filé com pele) foram inferiores aos encontrados na literatura que variam de $25,4 \%$ até valores de $42 \%^{5}$. Neste trabalho, a filetagem foi executada por pessoas não treinadas, o que contribuiu para o baixo rendimento do filé.

A pele é importante porque várias espécies são comercializadas sob a forma de filé com pele, no entanto a tilápia não é comercializada desta forma. Segundo CONTRERAS-GUSMÁN ${ }^{6}$, a pele corresponde a $7,5 \%$ do peso dos peixes ósseos. A porcentagem de pele bruta obtida neste experimento foi de $3,68 \%$, que foi inferior às relatadas na literatura por MACEDO-VIEGAS, SOUZA, KRONKA ${ }^{13}$, SOUZA et al. ${ }^{24}$, SOUZA e MARANHÂO ${ }^{27}$, PINHEIRO et al. ${ }^{18}$ cujas porcentagens variaram, respectivamente, de 4,77 a $5,71 \%, 6,54$ a $5,65 \%, 6,16$ a $6,56 \%$ e $8 \%$.

O rendimento da cabeça obtido neste experimento foi de $29,14 \%$. Este valor é bem próximo ao encontrado na literatura por MACEDO-VIEGAS, SOUZA, KRONKA ${ }^{13}$, que encontraram valores de no mínimo $25,41 \%$ para a categoria de peso de (401-450 g) e no máximo de $29,02 \%$ para tilápias do Nilo pesando entre 301-350 g. Estes autores citam que a categoria de peso não influencia na porcentagem de cabeça. SOUZA et al. ${ }^{24}$ relatam que a categoria de peso influencia na percentagem de cabeça da tilápia do Nilo, sendo a maior porcentagem (30,67\%) observada na categoria de 250 a 400 g comparada com $27,07 \%$ referente à categoria de (401-550 g).

Alguns autores ${ }^{19,23,25,26}$ citam que a faixa de peso influencia o rendimento do filé. Por exemplo, RIBEIRO, LIMA e TURRA ${ }^{19}$ encontraram um rendimento mínimo de $26,32 \%$ e no máximo de $37,08 \%$ para a tilápia vermelha (Oreochromis sp.) e observaram que o rendimento do filé aumentou em função do peso do peixe, sendo de $31,49 \%$ na menor classe (150-350 g) e de $33,67 \%$ na maior classe (751-950 g). SOUZA, MACEDOVIEGAS, KRONKA ${ }^{25,26}$ e SOUZA $^{23}$ relataram diferenças no rendimento de filetagem de acordo com as categorias de peso. Por outro lado, SOUZA e MARANHÃO ${ }^{27}$ não encontraram diferença significativa para o rendimento de filés de tilápia nilótica na faixa de peso estudado que foi de $36,5 \%$ para $300-400 \mathrm{~g}$ e $36,84 \%$ para a faixa de peso de $401-500$ g. Igualmente, PINHEIRO et al..$^{18}$ também não encontrou diferença significativa no rendimento de filé de tilápia tailandesa entre as categorias de peso, (300-600 g), (601-800 g) e (801-1000 g).

Os resíduos (cabeça + espinha) corresponderam em média a $55,85 \%$ do total do pescado, o que torna importante o seu aproveitamento.

A Tabela 5 mostra a distribuição de peso da tilápia tailandesa em 3 faixas de peso. Os valores de rendimento dos filés com e sem pele na faixa de peso estudada não diferiram estatisticamente em si no teste de Tukey $(p>0,05)$.

Tabela 5. Rendimento médio do filé de tilápia tailandesa com e sem pele em função da distribuição do peso.

\begin{tabular}{cccc}
\hline $\begin{array}{c}\text { Número de } \\
\text { exemplares }\end{array}$ & $\begin{array}{c}\text { Faixa de } \\
\text { peso }(\mathrm{g})\end{array}$ & $\begin{array}{c}\text { Rendimento médio } \\
\text { do filé sem pele }(\%)\end{array}$ & $\begin{array}{c}\text { Rendimento médio } \\
\text { do filé com pele (\%) }\end{array}$ \\
\hline 2 & $440-760$ & $16,43 \pm 2,80$ & $21,49 \pm 1,50$ \\
9 & $760-1080$ & $17,27 \pm 1,36$ & $21,51 \pm 1,68$ \\
8 & $1080-1400$ & $17,51 \pm 1,20$ & $21,74 \pm 0,95$ \\
\hline
\end{tabular}

O rendimento de filé, além da eficiência das máquinas filetadoras ou da destreza manual do operário, depende de algumas características intrínsecas à matéria-prima, ou seja, da forma anatômica do corpo, do tamanho da cabeça e dos pesos dos resíduos (vísceras, pele e nadadeiras) ${ }^{6,9,19}$.

SOUZA $^{22}$ encontrou diferenças significativas quando comparou seis métodos de filetagem, em relação ao rendimento de filé e de subprodutos do processamento da tilápia do Nilo. O melhor método de filetagem foi o que retirou a pele do peixe inteiro e depois removeu o filé.

\subsection{Caracterização físico-química da matéria-prima}

A Tabela 6 mostra a caracterização físico-química da tilápia.

Os valores médios da composição química da matériaprima estão mostrados na Tabela 6. Os resultados foram próximos aos encontrados por YANAR, CELIK e AKAMCA ${ }^{30}$ para a tilápia (Oreochromis niloticus) que apresentou $76,87 \%$ 
Tabela 6. Caracterização físico-química dos filés de tilápia.

\begin{tabular}{cr}
\hline Análise & \multicolumn{1}{c}{ Média } \\
\hline Umidade $\left(\mathrm{g} .100 \mathrm{~g}^{-1}\right)$ & $77,13 \pm 0,22$ \\
Lipídios $\left(\mathrm{g} .100 \mathrm{~g}^{-1}\right)$ & $2,60 \pm 0,35$ \\
Proteína $\left(\mathrm{g} .100 \mathrm{~g}^{-1}\right)$ & $19,36 \pm 0,49$ \\
Cinza $\left(\mathrm{g} .100 \mathrm{~g}^{-1}\right)$ & $1,09 \pm 0,02$ \\
Atividade de água & $0,983 \pm 0,001$ \\
\hline
\end{tabular}

de umidade, $18,23 \%$ de proteína, 2,64\% de lipídios e 1,09\% de cinza. Estes resultados também estão próximos aos encontrados por SALES e SALES ${ }^{20}$ que encontraram para a tilápia valores de umidade $75 \%$, 18,5\% de proteína, 3,60\% de lipídios e $2,4 \%$ de cinzas.

CONTRERAS-GUZMÁN ${ }^{6}$ relata que a fração de cinzas em peixes de água doce apresenta variações em quantidades que vão de 0,90 a 3,39\%. Este valor é compatível ao valor de cinzas encontrado na tilápia. Com relação aos minerais, a carne de pescado é considerada uma fonte valiosa de cálcio e fósforo particularmente, apresentando também quantidades razoáveis de sódio, potássio, manganês, cobre, cobalto, zinco, ferro e iodo.

OGAWA e MAIA ${ }^{16}$ citam que o músculo do pescado pode conter de 60 a $85 \%$ de umidade, aproximadamente $20 \%$ de proteína, de 1 a $2 \%$ de cinza, de 0,3 a 1,0\% de carboidrato e de 0,6 a $36 \%$ de lipídios. Este último componente apresenta uma maior variação em função do tipo de músculo corporal em uma mesma espécie (por exemplo, em atum a carne dorsal apresenta teores de 1 a $2 \%$ de lipídeos, enquanto que a carne abdominal pode alcançar até $20 \%$ ), sexo, idade, época do ano, habitat e dieta entre outros fatores.

Segundo PIGOTT e TUCKER ${ }^{17}$, uma forma de definir a classificação de peixes gordos está baseada na seguinte relação: menor que $2 \%$ de conteúdo de lipídeos, é um pescado de baixo conteúdo de gordura; entre 2 e $5 \%$, é um pescado moderado em conteúdo de gordura; e maiores que 5\%, é considerado um pescado com alto conteúdo de gordura. Os resultados classificam a tilápia tailandesa como um pescado com moderado teor de gordura.

A atividade de água encontrada foi de 0,983 , que foi inferior ao valor encontrado por SOUZA et al. ${ }^{28}$ para tilápia do Nilo, sendo portanto classificado como um alimento com alto teor de umidade ${ }^{10}$.

\section{Conclusões}

- os exemplares de tilápia tailandesa apresentaram, em sua composição, moderados teores de lipídios e elevados teores de proteínas, sendo assim caracterizado como um pescado com teor intermediário de gordura e de alto valor protéico;

- A faixa de peso não influenciou o rendimento do filé;

- O rendimento com e sem pele do filé foram inferiores aos encontrados na literatura; e

- Os resíduos obtidos foram em média de 55,85\%, sendo importante o seu aproveitamento na produção de ração, ensilados, etc.

\section{Agradecimentos}

À UNICAMP, FAPESP, CNPq e Universidade Estadual do Oeste do Paraná (UNIOESTE).

\section{Referências bibliográficas}

1. ANVISA (Agência de Vigilância Sanitária). Regulamento Técnico Sobre Padrões de Qualidade para Alimentos. Resolução-RDC. n. 12, de 02 de janeiro de 2001.

2. AOAC. (Association Official Analytical Chemists). Official Methods of Analysis. 16 ${ }^{a}$ ed., Arlington, 1997.

3. BRUSHI, F. L. F. Rendimento, composição química e perfil de ácidos graxos de pescados e seus resíduos: uma comparação. Itajaí: Universidade do Vale do Itajaí. (monografia). 2001, 65 p.

4. CAStagnolli, N. Piscicultura de água doce. Jaboticabal: Funep, 1992.

5. CLEMENT, S.; LOVELL, R. T. Comparison of culture Nile tilapia (Oreochromis niloticus) and channel catfish (Ictalurus punctatus). Aquaculture, Amsterdam, v. 119, n. 2-3, p. 299-310, 1994.

6. CONTRERAS-GUZMÁN, E. S. Bioquímica de pescados e derivados. Jaboticabal: FUNEP, 1994.

7. CUNHA NETO, A.; SILVA, C. G. M.; STAMFORD, T. L. M. Staphylococcus Enterotoxigênicos em Alimentos in natura e processados no Estado de Pernambuco, Brasil. Ciência e Tecnologia de Alimentos, v. 22, n. 3, p. 263-271, 2002.

8. DAMS, R. I.; BEIRÃO, L. H.; TEIXEIRA,E. Avaliação da qualidade microbiológica da pescadinha (Cynoscion striatus) inteira e em filés nos principais pontos críticos de controle de uma indústria de pescado congelado. Boletim do Centro de Pesquisa e Processamento de Alimentos. v. 14, n. 2, p. 151-162, 1996.

9. EYO, A. A. Carcass composition and filleting yield of ten fish species from Kainji Lake: proceedings of the FAO expert consultation on fish technology in Africa. FAO fishers Report, Rome, n. 467, p. 173-175, 1993. Supplement.

10. FERnANDEZ-SAlGUero, F.; GÓMEZ, R.; CARMONA, M. A. Water activity in selected high -moisture foods. J. Food. Comp. Anal., v. 6, n. 4, p. 364-369, 1993.

11. HYLUY, D. J. et al. Avaliação da qualidade dos produtos pesqueiros no Estado do Ceará. Higiene Alimentar, v. 10, n. 45, p. 37, 1996.

12. LEITÃO, M. F. de F. Microbiologia do pescado e controle sanitário no processamento. Boletim do Instituto de Tecnologia de Alimentos, v. 14, n. 50, p. 1-35, 1977.

13. MACEDO-VIEGAS, E. M; SOUZA, M. L. R.; KRONKA, S. N. Estudo da carcaça de tilápia do Nilo (Oreochromis niloticus), em quatro categorias de peso. Revista Unimar, Maringá, v. 19, n. 3, p. 863-870, 1997.

14. MOREIRA, H. L. M. Análise da estrutura de populações e diversidade genética de estoques de reprodutores de tilápia do Nilo (Oreochromis niloticus) estimadas por microsatélite. 1999. Tese (Doutorado em Genética e Biologia Molecular) Universidade Federal do rio Grande do Sul, Porto Alegre.

15. NUGENT, C. Session II, The status of wild and cultured tilapia genetic resources in various contries. In: PULLIN, R. S. V. et al. (Ed.) The Second International Symposium on Tilapia in Aquaculture. Manilla, Philippines. Proccedings... Manilla, Philippines: ICLARM, 1988. p. 20-21. (ICLARM Conference Proccedings, $\mathrm{n}^{\circ} 15$ ). 
16. OGAWA, M.; MAIA, E. L.; Manual de Pesca., Ciência e Tecnologia do Pescado. São Paulo, Varela, 1999, v. 1, 453 p.

17. PIGOT, G; TUCKER, B. Sea food effects of technology on nutrition, $1^{\text {st }}$ edit, Edit Marcel Dekker, INC, New York, USA, 1990.

18. PINHEIRO, L. M. S. et al., Rendimento industrial de filetagem da tilápia tailandesa (Oreochromis spp.) Arq. Bras. Med. Vet. Zootec., v. 58, n. 2, p. 257-262, 2006.

19. RIBEIRO, L. P. et al. Efeito do peso e do operador sobre o rendimento de filé em tilápia vermelha spp. In: AQÜICULTURA BRASIL 98, 1998, Recife. Anais... Recife: ABRAq, 1998. v. 2, p. $773-778$.

20. SALES, R. de O., SALES, A. M.; Estudo da composição química e rendimento de dez espécies de água doce de interesse comercial nos açudes do nordeste brasileiro. Ciências Agronômicas. v. 1/2, n. 21, p. 27-30, 1990

21. SANTOS, V. B.Crescimento morfométrico e alométrico de linhagens de tilápia (Oreochromis niloticus). Dissertação de mestrado. 2004. 86 p. UFLA, Lavras.

22. SOUZA, M. L. R. Comparação de Seis Métodos de Filetagem, em Relação ao Rendimento de Filé e de Subprodutos do Processamento da Tilápia-do-Nilo (Oreochromis niloticus). Revista Brasileira de Zootecnia., v. 31, n. 3, p. 1076-1084, 2002.

23. _ Processamento do filé e da pele da Tilápia do Nilo (Oreochromis niloticus): Aspectos tecnológicos, composição centesimal, rendimento, vida útil do filé defumado e testes de resistência da pele curtida. 2003. 166 p. Tese (Doutorado) Centro de Aqüicultura, UNESP, Jaboticabal.

24. SOUZA, M. L. R. et al. Rendimento do processamento da tilápia do Nilo (Oreochromis niloticus): tipos de cortes de cabeça em duas categorias de peso. Acta Scientiarum, Maringá, v. 22, n. 3, p. 701-706, 2000.

25. SOUZA, M. L. R., MACEDO-VIEGAS, E. M.; KRONKA, S. N. Efeito do método de filetagem e categorias de peso sobre o rendimento de carcaça, filé e pele da tilápia do Nilo (Oreochromis niloticus). In: Reunião Anual da Sociedade Brasileira de Zootecnia, 34., 1997, Juiz de Fora. Anais... Juiz de Fora: SBZ, 1997a.

$26 . \quad$ ___ Estudo da carcaça da tilápia do Nilo (Oreochromis niloticus) em diferentes categorias de peso. In: Reunião Anual da Sociedade Brasileira de Zootecnia, 34., 1997, Juiz de Fora. Anais... Juiz de Fora: SBZ, 1997b.

27. SOUZA, M. L. R.; MARANHÃO, T. C. F. Rendimento de carcaça, filé e subprodutos da filetagem da tilápia do Nilo, Oreochromis niloticus (L), em função do peso corporal. Acta Scientiarum. Maringá, v. 23, n. 4, p. 897-901, 2001.

28. SOUZA, M.L. R. et al. Efeito do peso de tilápia do Nilo (Oreochromis Niloticus) sobre o rendimento e a qualidade de seus filés defumados com e sem pele. Ciência e Tecnologia de Alimentos, Jan./Mar., v. 25, n. 1, p. 51-59, 2005.

29. VIEIRA, K. V. M. et al. Influência das condições higiênico-sanitárias no processo de beneficiamento de tilápias (Oreochromis niloticus) em filés congelados. Higiene Alimentar, v. 14, n. 74, p. 37-40, 2000.

30. YANAR Y.; CELIK, M.; AKAMCA, E. Efects of brine concentration on shelf-life of hot-smoked tilapia (Oreochromis niloticus) stored at $4{ }^{\circ} \mathrm{C}$. Food Chemistry v. 97, n. 2 p. $244-247,2006$.

31. ZIMMERMANN, S. Incubação artificial: técnica permite a produção de tilapia-nilo geneticamente superiores. Panorama da Aqüicultura, Rio de Janeiro, v. 9,n. 54,p. 15-21,1999. 